\title{
Creative Leadership for Directing Changes
}

\author{
Kuan Chen Tsai \\ Dreeben School of Education, University of the Incarnate Word \\ 4301 Broadway, San Antonio, TX 78209, USA \\ E-mail: ktsai@student.uiwtx.edu
}

Received: October 25, 2012 Accepted: October 29, 2012 Published: December 31, 2012

doi:10.5296/bms.v3i2.2936 URL: http://dx.doi.org/10.5296/bms.v3i2.2936

\begin{abstract}
With technological superiority and globalization, critical changes in the world have lead to uncertainty and ambiguity towards the future. By understanding these dynamics, creative leaders position themselves to lead organizations toward a more desirable direction. Specifically, leaders play a dual role to facilitate employees' creativity and organizational innovation. The aim of this paper is to highlight the importance of creative leadership in organizational settings, especially for the purpose of confronting turbulence and fast-changing environments. It starts by discussing the definition of creative leadership. It then moves on to discuss three theoretical frameworks related to creativity, considering wider implication for creative leadership. The paper concludes with some barriers and useful tactics for the implementation of creative leadership for directing change.
\end{abstract}

Keywords: Creativity, Innovation, Creative leadership 


\section{Introduction}

With technological superiority and globalization, critical changes in the world have lead to uncertainty and ambiguity towards the future. Because of these expressions of concern, Nanus (1990) argued that the demand for creative leadership is to "embrace this uncertainty because it opens up new possibilities and opportunities" (p. 14). By understanding these dynamics, creative leaders position themselves to lead organizations toward a more desirable direction.

Kanter (1986) believed that instead of utilizing creativity training in corporate settings, the corporate environment plays a more important role in modeling creativity. Specifically, "any leader can design an environment that helps ordinary people become more creative" (p. 11). For Kanter (1986), creativity is like "kaleidoscope thinking" (p. 11) and the key to creativity is to rearrange the structure to create a new reality. She explained that "the kaleidoscope is a wonderful metaphor for the creative process because the gadget allows us to twist reality into new patterns.... All you have to do is shake it, twist it, change angle, change perspective, and the exact same fragments from an entirely new pattern. Reality, the kaleidoscope tells us, is only a temporary arrangement" (p. 11). Kanter (1986) argued that "every creative act is a form of play - playing with ideas, twisting the kaleidoscope of reality" (p. 12).

There has been a strong sentiment among creativity scholars that environmental and social factors have a significant and complex impact on creativity (Amabile, 1997; Cummings \& Oldham, 1997; Ekvall \& Ryhammar, 1999). Specifically, leaders play a key role in facilitating creativity in individuals and groups (Harding, 2010; Sosik, Kahai, \& Avolio, 1998; Sternberg, 2005). The aim of this paper is to highlight the importance of creative leadership in organizational settings, especially for the purpose of confronting turbulence and fast-changing environments. It starts by discussing the definition of creative leadership. It then moves on to discuss three theoretical frameworks related to creativity, considering wider implication for creative leadership. The paper concludes with some barriers and useful tactics for the implementation of creative leadership for directing change.

\section{The Nature of Creative Leadership}

Stoll and Temperley (2009) explained that creative leadership is "an imaginative and thought-through response to opportunities and to challenge issues that inhibit learning at all levels.... Creative leaders also provide the condition, environment, and opportunities for others to be creative" (p. 66). The Center for Creative Leadership (2012) defined creative leadership as "the capacity to think and act beyond the boundaries that limit our effectiveness." In addition, Ibbotson and Dars $\varnothing$ (2008) have recognized in reality that behaviors of encouraging autonomy and using constraints should go hand in hand. They argued that creative leadership is "a balancing act between the emergent and the directed" (p. 552). Therefore, the craft of creative leadership is rooted in being able to "identify, articulate, and express constraints that provoke the team to creative responses within the right field" (pp. 554-555). In short, they believed the use of creative constraint is a vehicle leading people to think outside the box and to create innovation.

According to Imison (2001), the attempt of creative leaders is to "challenge existing 
assumptions and perceptions" (p. 145), thereby constructing or reconstructing new ideas and being innovative. Powell (2008) also pointed out in order to understand the dynamic relationships within an organization, its capacities, and markets, it is necessary for creative leaders to share advanced expertise and creative problem- solving skills to be able to lead creative employees, thereby producing a creative product. In educational settings, Joubert (2001) argued that "creative leadership can engender an ethos of valuing creativity in school which could lead to a school culture characterized by an emphasis on mobility of ideas and flexibility of perspective" (p. 26).

Mumford, Scott, Gaddis, and Strange (2002) have differentiated creative leadership and other leadership behaviors in three perspectives: (a) the nature of work, specifically, novel, ill-defined tasks; (b) different influence tactics that direct creative people; and (c) the inherent tension between creative efforts and organizational demands. According to the literature review, they found leaders' technical expertise and creative problem-solving capacities pertain to better leader and group performance. In addition, they have identified that the nature of creative work is person-centered, requires collaborative efforts, is demanding and time consuming, resource intensive, necessitates uncertain and risky ventures, and is contextualized (pp. 708-709). Two sets of tactics are leading people and leading the work; the former is related to facilitate and stimulate creative people to follow the expected directions, whereas the latter is about mechanisms applied to ensure producing expected results. Finally, Mumford and colleagues (2002) maintained that creative leadership is an integrative style of leadership with three elements: idea generation, idea structuring, and idea promotion. In short, as Mumford et al (2002) suggested, “organizations may now need jazz group leaders rather than orchestra directors" (p. 737) to reflect the interactive and participative mechanisms between leaders and followers for creativity and innovation in organizational settings.

Goertz (2000) has recognized that a conceptual link between creativity and leadership for defining creative leadership in literature is seldom found. Specifically, if creators in the position of leadership, their creativity will function as an important asset for exercising leadership. In this case, creativity becomes a means of leadership. According to selected creativity traits from the literature, Goertz (2000) wrote:

Effective leadership is orchestrating the totality of the enterprise with creativity traits of passion for work, independence, goal setting, originality, flexibility, wide range of interests, intelligence and creativity, and motivation.... These traits suggest the creative leader is an encourager and motivator of people. The creative leader guides group activities toward common goals. The creative leader is a skillful master of motivation, and able to nurture a deep sense of commitment and drive among her followers, who then attempt to achieve the unachievable. (p. 161)

The hallmark of creative leadership is creative problem solving. In organizational settings, because of restrictions imposed by time, resources, and demands, leaders face more challenges in solving problems in this complex context. Mumford and Connelly (1999) stated that 'leaders' creative problem solving, as a result, is a highly social phenomenon that places a premium on consensus building, persuasion, and creation of a shared vision that can be 
accepted by the relevant constituencies" (p.141).

Another core value of creative leadership is to give license for others to be creative. This movement empowers people to develop their creativity capacity in learning and leading. The credibility of creative leadership is grounded in the fact that people are allowed to show their creativity and trust their abilities. Taken as a whole, as Mumford and Connelly (1999) stated, "creativity may be an essential component of effective organizational leadership. Not only do leaders need a set of complex creative thinking skills to solve novel, ill-defined organizational problems, they must be able to interact with followers in ways that encourage and manage subordinate creativity" (p. 144). In sum, Harding (2010) asserted that "the most significant skills that a leader can possess are the ability to think creatively and inspire creativity in others" (p. 53). Therefore, the essence of creative leadership is grounded in the belief that leaders not only utilize their creativity but also employs tactics to maximize creativity of followers (Clapham, 2000; Jung, 2000).

\section{The Implication of Three Systems-Oriented Models for Creative Leadership}

Robinson and Runco (1992) proposed a psychoeconomic model of the creative process. This economic theory of creativity attempts to link the human capital approach from economics into the concept of creative potential from psychology and attempts to explain variations between the costs of an individual producing creative products and the benefits of this outcome. This framework postulates that "the existence of a creative potential for each individual as the product of some initial endowments (based on both genotype and environment) and investments the individual may make in learning creative modes of thinking" (p. 132) and leads to "an economic model of the markets for creative activity" (p. 132). According to the implication of this model, they suggest that "society as a whole would be better off shifting some resources from other areas into the creative sphere" (p. 133).

Sternberg and Lubart's $(1993,1995)$ investment theory of creativity posited that the creative person should act like a good investor and "buy low and sell high." The creative individual, metaphorically, buys low by rejecting accepted ideas in the society, and then sells high when others realize its value and follow the thread. The notion of selling ideas signifies the social environment as an important variable in creativity. They believed the ideas are rejected because creative individuals define the crowd and make people fail to recognize its interests because of uncomfortably embracing their ideas. According to this model, they also recognized six potential resources that help or hinder creativity: intellectual processes, knowledge, intellectual style, personality, motivation, and environmental context.

From the perspective of creative problem solving, Mumford and Connelly (1999) suggested three distinct components might play a role in creative leadership: problem-focused cognition, organizational cognition, and social cognition. They believed it is a mistake to equate creative efforts of leaders with other creative achievements like arts and sciences. The main difference is that leaders need to formulate workable solutions that fit the demands from organizations and societies. Mumford and Connelly (1999) asserted the key role of creative leaders is to solve novel and ill-defined organizational problems. Therefore, problem-focused and organizational cognition are an imperative tenet of their tripartite model. However, they recognized the 
importance of interaction between leaders and followers. In order to build consensus and resolve conflict, leaders need to take the social context into consideration within interactions.

These three models, presented through either an economic metaphor or organizational behavior, provide broad implications for creative leadership. First, they suggest creative leaders should reward and value employees who generate creative ides, thereby encouraging employees to buy low and sell high in their ideas. Second, by cultivating an environment conducive to innovation, leaders should make structural and policy changes that harness creativity for the organization's benefit. Third, leaders should recognize that creative performance is related to employees having the right attitude instead of people having the right profile of abilities. In other words, the expression of an individual's creative potential should be encouraged. Finally, the responsibility of creative leaders is not only to demonstrate their creativity to deal with ambiguous issues, but also to try to persuade others to share their creative insights. Only by offering positive attitudes and incentives can creative individuals be prodded toward creative production.

\section{Some Barriers Embedded in Organizational Culture for Actualization of Creative Leadership}

It is not an easy task for leaders to implement the idea of creativity in organizational settings. Nahavandi (2009) has identified several obstacles to effective leadership: (a) organizations face considerable uncertainty that creates pressure for quick responses and solutions. In an atmosphere of crisis, there is no time or patience for learning; (b) organizations are often rigid and unforgiving. They do not allow any room for mistakes and experimentation; (c) organizations have a tendency to rely on simplistic solutions that do not fit new and complex problems; and (d) over time, all organizations develop a particular culture that strongly influences how things are done and what is considered acceptable behavior (p. 9).

Williams and Yang (1999) have identified that structural obstacles to creativity and innovation stem from the idea of division of labor, which was proposed by Adam Smith (1776/1996), for the purpose of optimal structure of organizations and from another classic conceptualization of bureaucracy, which was proposed by Weber (1922/1996). Williams and Yang (1999) asserted that "inadvertently, Smith and Weber contributed to many of the structural obstacles that hinder the process of innovation and creativity in an organizational context. The structures they proposed encourage rigid adherence to rules and regulations. This emphasis encourages conservative thinking and can hinder effective problem solving and information flow" (p. 375). As a result, they suggested that a key role of creativity is for organizational functioning and decision making.

Another issue is selection process. Top management often will select candidate leaders who are similar to them. Therefore, Kanter (1986) pointed out that people will spend a lot of time with others just like them when they enter the field. Most important, leaders from top management spend more time with people exactly like themselves. As a result, they contact people outside the field who challenge and force them to confront their beliefs and assumption. Most often, leaders are likely to shut down the contact because they feel insulated from unpleasant experiences by those outsiders. 


\section{Fueling Organizational Changes through Creative Leadership}

Kanter (1986) has identified the essence of organizational change process and stated that "organizational change consists in part of a series of emerging constructions of reality, including revision of the past, to correspond to the requisites of new players and new demands" (p. 21). In addition, Kanter (1985) noticed the necessity of change and stated that "change, and the need to manage it well, has always been with us. Business life is punctuated by necessary and expected changes" (p. 52). However, as she recognized, people have a tendency to refute change because "tension, stress, squabbling, sabotage, turnover, subtle undermining, behind-the scenes foot-dragging, work slowdowns, needless political battles, and a drain on money and time - in short, symptoms of that ever-present bugaboo, resistance to change" (p. 52).

Kanter (1985) has recognized several factors that cause employees to resist change: loss of control, excess uncertainty, surprise, the difference effect, loss of face, concerns about future competence, ripple effects, increase of workload, past resentments, and real threat (pp. 52-56). Additionally, in order to propose a better position to invent solutions to deal with these issues, thereby managing change smoothly and effectively, she provided several suggestions: employing participative management, providing enough information to build commitment to change, arranging the timing of the information's release, minimizing the number of differences introduced by the change, ensuring that past actions are put in perspective, providing sufficient education and training as positive reinforcement, supporting the compensation for the extra work of change, and sweeping away the cobwebs of the past (pp. 52-56).

Powell (2008) observed several important tasks of creative leaders that are conducive for creativity to be operated in alignment with the objectives and visions of organizations, including intrinsic and extrinsic motivation, evaluation and feedback, and risk and trust. Taken as a whole, he remarked that creative leaders are not mavericks within the organizations; instead, they need to obtain support from stakeholders (employees, peers, organizations, and consumers) to sell their creative ideas and solutions for the benefits of all.

Stoll and Temperley (2009) suggested that modeling is an effective approach that leaders could utilize to lead others' learning and development. Rui, Emerson, and Luis (2010) maintained that in order to promote innovation in organizations, the concept of a learning cycle should be incorporated into policies and structures of organizations. It involves "experimenting process, experience, reflection, and consolidation.... [Thus] it is important to create the conditions so that learning opportunities emerge and are explored" (p. 13). In short, Nahavandi (2009) clearly claimed that "creativity for leaders and followers is a key factor in organizational ability to innovate and change" (p. 313). Therefore, for organizational change, creative leadership could serve as a useful vehicle to facilitate this transition phrase and minimize the side effects of the change.

\section{Conclusion}

Stoll and Temperley (2009) remarked that creative leadership is a "disciplined process, planned 
for and purposeful, and geared towards engendering creativity" (p. 75). Good leadership creates meaning. Leadership delicately deals with values, visions, and goals and not merely with technical matters. Mayfield and Mayfield (2008) believed that "organizational survival is contingent on an organizational culture that embraces creativity at all performance levels" ( $p$. 983). As a result, the call for creativity in organizations is to meet the mounting pressures of business environment, especially facing the plateau of innovation. Organizations should use economic ways to boost creativity (Mayfield \& Mayfield, 2008). It is believed that creative leadership could boost this momentum for leading change. After all "leaders are an important facet of the work context for creativity [and innovation]" (Tierney, Farmer, \& Graen, 1999, p. 592).

\section{References}

Amabile, T. M. (1997). Motivating creativity in organizations: On doing what you love and loving what you do. California Management Review, 40(1), 39-58.

Center for Creative Leadership. (CCL, 2012). Welcome to the Center for Creative Leadership. Retrieved from http://www.ccl.org/leadership/about/index.aspx

Clapham, M. M. (2000). Employee creativity: The role of leadership. The Academy of Management Executive, 14(3), 138-139.

Cummings, A., \& Oldham, G. R. (1997). Enhancing creativity: Managing work contexts for the high potential employee. California Management Review, 40(1), 22-38.

Ekvall, G., \& Ryhammar, L. (1999). The creative climate: Its determinants and effects at a Swedish university. Creativity Research Journal, 12(4), 303-313.

Goertz, J. (2000). Creativity: An essential component for effective leadership in today's schools. Roeper Review, 22(3), 158-162.

Harding, T. (2010). Fostering creativity for leadership and leading change. Arts Education Policy Review, 111(2), 51-53. http://dx.doi.org/10.1080/10632910903455827

Ibbotson, P., \& Dars $\emptyset$, L. (2008). Directing creativity: The art and craft of creative leadership. Journal of Management and Organization, 14(5), 548-559.

Imison, D. T. (2001). Creative leadership: Innovative practices in a secondary school. In A. Craft, B. Jeffrey, \& M. Leibling (Eds.), Creativity in education (pp. 144-150). New York, NY: Continuum.

Joubert, M. M. (2001). The art of creative teaching: NACCCE and beyond. In A. Craft, B. Jeffrey, \& M. Leibling (Eds.), Creativity in education (pp. 17-34). New York, NY: Continuum.

Jung, D. I. (2000). Transformational and transactional leadership and their effects on creativity in groups. Creativity Research Journal, 13(2), 185-195.

Kanter, R. M. (1983). Change masters and the intricate architecture of corporate culture change. Management Review, 72(10), 18-28. 
Kanter, R. M. (1985). Managing the human side of change. Management Review, 74(4), 52-56.

Kanter, R. M. (1986). Creating the creative environment. Management Review, 75(2), 11-12.

Mayfield, M., \& Mayfield, J. (2008). Leadership techniques for nurturing worker garden variety creativity. The Journal of Management Development, 27(9), 976-986. http://dx.doi.org/10.1108/02621710810901318

Mumford, M. D., \& Connelly, M. S. (1999). Leadership. In M. A. Runco \& S. R. Pritzker (Eds.), Encyclopedia of creativity (pp. 139-145). San Diego, CA: Academic Press.

Mumford, M. D., Scott, G. M., Gaddis, B., \& Strange, J. M. (2002). Leading creative people: Orchestrating expertise and relationships. The Leadership Quarterly, 13(6), 705-750. http://dx.doi.org/10.1016/S1048-9843(02)00158-3

Nahavandi, A. (2009). The art and science of leadership (5th ed.). Upper Saddle River, NJ: Pearson Education.

Nanus, B. (1990). Futures-creative leadership. The Futurist, 24(3), 13-17.

Powell, S. (2008). The management and consumption of organizational creativity. The Journal of Consumer Marketing, 25(3), 158-166. http://dx.doi.org/10.1108/07363760810870653

Rubenson, D. L., \& Runco, M. A. (1992). The psychoeconomic approach to creativity. New Ideas in Psychology, 10, 131-147.

Rui, C., Emerson, M., \& Luis, L. (2010). Transformational leadership and TQM implementation. Advances in Management, 3(6), 7-18.

Smith, A. (1776/1996). Of the division of labour. In J. M. Shafritz \& J. S. Ott (Eds.), Classics of organization theory (pp. 40-45). Belmont, CA: Wadsworth.

Sosik, J. J., Kahai, S. S., \& Avolio, B. J. (1998). Transformational leadership and dimensions of creativity: Motivating idea generation in computer-mediated groups. Creativity Research Journal, 11(2), 111-121.

Sternberg, R. J. (2005). A model of educational leadership: Wisdom, intelligence, and creativity, synthesized. International Journal of Leadership in Education, 8(4), 347-364.

Sternberg, R. J., \& Lubart, T. I. (1993). Investing in creativity. Psychological Inquiry, 4(3), 229-231.

Sternberg, R. J., \& Lubart, T. I. (1995). Defying the crowd: Cultivating creativity in a culture of confomity. New York, NY: The Free Press.

Stoll, L., \& Temperley, J. (2009). Creative leadership: A challenge of our times. School Leadership \& Management, 29(1), 65-78. http://dx.doi.org/10.1080/13632430802646404

Tierney, P., Farmer, S. M., \& Graen, G. B. (1999). An examination of leadership and employee creativity: The relevance of traits and relationships. Personnel Psychology, 52(3), 591-620. 
http://dx.doi.org/10.1111/j.1744-6570.1999.tb00173.x

Weber, M. (1922/1996). Bureaucracy. In J. M. Shafritz \& J. S. Ott (Eds.), Classics of organization theory (pp. 80-85). Belmont, CA: Wadsworth.

Williams, W. M., \& Yang, L. T. (1999). Organizational creativity. In R. J. Sternberg (Ed.), Handbook of creativity (pp. 373-391). New York, NY: Cambridge University Press.

\section{Copyright Disclaimer}

Copyright reserved by the author(s).

This article is an open-access article distributed under the terms and conditions of the Creative Commons Attribution license (http://creativecommons.org/licenses/by/3.0/). 